\title{
Evidence for Excitatory and Inhibitory Amino Acids Participation in the Neuropharmacological Activity of Alpha- and Beta-Amyrin Acetate
}

\author{
Gislei F. Aragão a , Lyvia M.V. Carneiro ${ }^{\mathrm{a}}$, Antônio P.F. Junior ${ }^{\mathrm{a}}$, Paulo N. Bandeira ${ }^{\mathrm{b}}$, \\ Telma L.G. Lemos ${ }^{\mathrm{b}}$ and Glauce S. de B. Viana*,a \\ ${ }^{a}$ Department of Physiology and Pharmacology, Federal University of Ceará (UFC), Brazil \\ ${ }^{b}$ Department of Organic and Inorganic Chemistry (UFC), Rua Cel. Nunes de Melo, 1127. Fortaleza 60431-970, Brazil
}

\begin{abstract}
We evaluated the neuropharmacological profile of acetylated alpha- and beta-amyrin (AcAMY) obtained by the acetylation of the isomeric mixture of alpha- and beta-amyrin isolated from Protium heptaphyllum. Male Swiss mice were administered with AcAMY (2.5, 5, 10 and $25 \mathrm{mg} / \mathrm{kg}$, i.p.), and anticonvulsant (pentylenetrazole- and pilocarpine-induced convulsions), sedative (barbiturate-induced sleep and open field tests) and anxiolytic (elevated plus maze test) activities were studied. Results showed that AcAMY administered intraperitoneally or orally, protected the animals against pentylenetetrazole- but not against pilocarpine-induced convulsions. The drug increased both the latency to the $1^{\text {st }}$ convulsion and the latency to death. The barbiturate-induced sleeping time was also increased, as well as the ethyl ether-induced sleeping time, confirming the sedative nature of AcAMY. The acute administration of AcAMY also produced an anxiolytic effect. After the sub-chronic administration, both sedative and anxiolytic effects were manifested, at the two higher doses. Amino acids measurements in brain areas of mice treated with AcAMY ( $25 \mathrm{mg} / \mathrm{kg}$, i.p., for 7 days) showed an $89 \%$ increase in tyrosine levels, in the hippocampus. In the striatum, tyrosine and taurine were increased by 97 and $79 \%$, respectively, while decreases in the levels of aspartate, GABA and glutamate of 72,55 and $60 \%$, respectively were observed. In conclusion, our results showed that AcAMY presents sedative, anxiolytic and anticonvulsant properties. Although the drug mechanism of action is not completely clarified, it seems to involve a decrease in excitatory amino acids and an increase of inhibitory amino acids. Furthermore, the GABAergic system may also play a role.
\end{abstract}

Keywords: Burseraceae, Protium heptaphyllum, acetate of alpha- and beta-amyrin, sedative, anticonvulsant and anxiolytic effects.

\section{INTRODUCTION}

Protium heptaphyllum March. (fam. Burseraceae), a plant common to several regions of Brazil, is popularly used for inflammation. From the resin, an isomeric mixture of pentacyclic triterpenes, alpha- and beta-amyrin, is isolated [1]. Recently, we demonstrated the presence of sedative, anxiolytic and antidepressant activities in the mixture of alphaand beta-amyrin, that possibly involve the GABAergic as well as the noradrenergic systems [2].

The triterpenes alpha-amyrin acetate, beta-amyrin acetate and beta-amyrin were tested for their effects on the synthesis of 5-lipoxygenase products in human neutrophils. All the triterpenes reduced 5-HETE synthesis without effect on $\mathrm{LTB}_{4}$ synthesis. The relative effects suggest that 5-HETE inhibition can explain the antiarthritic activity possessed by these compounds [3].

Although the acetyl group may be easily removed metabolically, it may alter the biological activity of the original compound. Thus, it has been shown that acetylation can increase, decrease, or not change the compounds biological activity [4]. Acetylation and deacetylation studies on

*Address correspondence to this author at the Department of Physiology and Pharmacology, Federal University of Ceará (UFC), Rua Barbosa de Freitas, 60170-020, Fortaleza, Brazil; Tel: +55853366 8337; Fax: +55 85 3366 8333; E-mail: gbviana@live.com triterpenes from Dysoxylum malabaricum and D. beddomei indicated that all triterpenes examined showed an increased cytotoxicity with acetylation [5]. Others [6] demonstrated that acetyl- $\alpha$-boswellic acid and acetyl-11-keto- $\beta$-boswellic acid, pentacyclic triterpenes, downregulate TNF- $\alpha$ expression. Acetyl-boswellic acids (acetyl BA) are cytotoxic for human glioma cell lines [7], and are effective anticancer agents [8].

In the present work, the neuropharmacological profile of the alpha- and beta-amyrin acetate (AcAMY) obtained by acetylation of the isomeric mixture of alpha- and betaamyrin from $P$. heptaphyllum, was evaluated by the open field, elevated plus maze and barbiturate-induced sleeping tests, in order to assess locomotor, anxiolytic and sedative effects. We also used two experimental models of convulsions to evaluate anticonvulsant effects. Attempting to clarify the mechanism of action, through HPLC determination, we examined the concentrations of excitatory and inhibitory amino acids, in two cerebral regions, the hippocampus and striatum of mice treated with AcAMY for 7 days.

\section{METHODS}

Animals. Male Swiss mice (20-30 g) from the Animal House of the Federal University of Ceará were used throughout the experiments. Animals were housed under standard environmental conditions $\left(23 \pm 2^{\circ} \mathrm{C}\right.$, humidity $60 \pm$ $5 \%, 12 \mathrm{~h}$ light:12 h dark cycle), with free access to a com- 
mercial diet and water. Each animal was used only once. Control animals were administered with the suspension of $0.5 \%$ Tween 80 , in distilled water used as vehicle. Before its suspension, Tween 80 was weighted in order to give a $0.5 \%$ final concentration $(0.5 \mathrm{~g}$ in $100 \mathrm{~mL}$ of distilled water $)$. All experiments were performed according to the Guide for the Care and Use of Laboratory Animals, from the US Department of Health and Human Services, Washington, DC, 1985. The project was previously approved by the Animal's Ethics Committee, of the Faculty of Medicine of the Federal University of Ceará.

Plant Material. The resin of Protium heptaphyllum March was collected in the area of Crato, State of Ceará, Brazil, in November 2005, and authenticated by Dr. Afrânio G. Fernandes. A voucher specimen \# 28509 is deposited at the Prisco Bezerra Herbarium, Department of Biology, Federal University of Ceará, Brazil. The resin was obtained by incision made on the plant trunk.

Extraction and Isolation. The resin (20 g) was crushed with silica gel $(20 \mathrm{~g})$, placed in a chromatography column and eluted with the following solvents: hexane $(50 \mathrm{~mL})$, chloroform $(50 \mathrm{~mL})$, ethyl acetate $(50 \mathrm{~mL})$ and methanol $(30$ $\mathrm{mL})$. The chloroform fraction $(5.2 \mathrm{~g})$ was repeatedly chromatographed on silica gel (30 g), and eluted with a mixture of hexane-ethyl acetate $(0-100 ; \mathrm{v} / \mathrm{v})$. The fractions eluted with hexane-ethyl acetate $(1: 1 ; \mathrm{v} / \mathrm{v})$ were purified by recrystallization with ethyl ether to afford $450 \mathrm{mg}$ of a mixture identified by spectroscopic data as alpha- and beta-amyrin [9]. The percentages of each component present in the mixture were determined by ${ }^{1} \mathrm{H}$ NMR spectroscopy, based on the integration measure (three times) of absorption of $\delta_{\mathrm{H}-12}(5.10$ and $5.16 \mathrm{ppm}$ ) for alpha- and beta-amyrin, respectively. The mixture was quantified as having $67 \%$ of alpha- and $33 \%$ of beta-amyrin.

Acetylation of alpha- and Beta-Amyrin. The alphaand beta-amyrin $(0.23 \mathrm{mmol})$ mixture (Fig. 1, 1/2) and $\mathrm{Ac}_{2} \mathrm{O}$ /pyridine $(2 \mathrm{~mL}: 1 \mathrm{~mL})$ were stirred at room temperature, for a period of $24 \mathrm{~h}$, and washed with a copper sulfate solution $(20 \mathrm{~mL})$. The reaction product was extracted with diethyl ether $(20 \mathrm{~mL})$, followed by solvent evaporation under reduced pressure to afford $98.6 \mathrm{mg}$, meaning that $100 \%$ of the mixture of alpha- and beta-amyrin were acetylated (1a/2a, Fig. 1). The acetylated material was first analyzed by TLC, and presented a different Rf value as compared to the starting material $(\mathbf{1} / \mathbf{2})$. The acetylated material was identified by physical and spectroscopic data as 3-O-Acetyl- $\alpha / \beta$ amyrin $(\mathbf{1 a} / \mathbf{2 a})$. The quantification of the mixture $1 \mathbf{a} / \mathbf{2} \mathbf{a}$ (3$O$-Acetyl- $\alpha / \beta$-amyrin) was done based on ${ }^{1} \mathrm{H}$ NMR by the ratio measure (three times) of peak absorptions: $\mathrm{H}-12$ at $\delta_{\mathrm{H}}$ $5.15 \mathrm{ppm}$ for 1a (alpha isomer) and $5.20 \mathrm{ppm}$ for $\mathbf{2 a}$ (beta isomer), and defined as 64\%:36\% for the 1a/2a mixture. This mixture was confirmed by IR analysis to be $100 \%$ acetylated. This method identified an absorption in $1735 \mathrm{~cm}^{-1}$ of stretch $\mathrm{C}=\mathrm{O}$ for ester and the absence of the absorption of stretch $\mathrm{O}-\mathrm{H}(\mathbf{1} / \mathbf{2})$. This was followed by analysis of ${ }^{13} \mathrm{C}$ NMR data, where the absorption of C-3 was observed at $\delta_{\mathrm{C}-3}$ 79.0 , characteristic of $\mathbf{1} / \mathbf{2}$, and a presence of absorption at $\delta_{\mathrm{C}-3} 81$ for $\mathbf{1 a} / \mathbf{2 a}[1]$, confirmed by EI-MS.

The mixture of alpha- and beta-amyrin (1/2) is a white amorphous powder, m.p. $179-181^{\circ} \mathrm{C}$; IR $(\mathrm{KBr}) v_{\max } \mathrm{cm}^{-1}$ 3300, 1480 and 1050; and ${ }^{1} \mathrm{H}$ and ${ }^{13} \mathrm{C}$ NMR $\left(\mathrm{CDCl}_{3}\right)$ agree with literature data $[1,9]$. 3-O-Acetyl- $\alpha / \beta$-amirin $(\mathbf{1 a / 2 a})$ is a white amorphous powder, m.p. $192-193.5^{\circ} \mathrm{C}$; IR (KBr) $v_{\max }$. $\mathrm{cm}^{-1}$ 2949, 1735, 1654, 1370, 1247, 1025); EI-MS: m/z 468 $\left(\mathrm{M}^{+}, 8.0 \%\right) ; 409$ (9.7); 218 (100); 203 (33.9); 189 (25); 43 (32); and ${ }^{1} \mathrm{H}$ and ${ }^{13} \mathrm{C}$ NMR are also in agreement with the literature $[1,10]$.

Melting points (m.p.) were determined by a digital Mettler Toledo FP90 apparatus. IR spectra were obtained on a Perkin-Elmer FT-IR Spectrum 1000. EI-MS was obtained by direct insertion on a Shimadzu spectrometer at $70 \mathrm{eV}$. NMR spectra were done in $\mathrm{CDCl}_{3}$ on a Bruker Avance DRX-500 $\left(500 \mathrm{MHz}\right.$ for ${ }^{1} \mathrm{H}$ and $125 \mathrm{MHz}$ for ${ }^{13} \mathrm{C}$ ) spectrometer. Silica gel 60 (70-230 mesh, VETEC, Brazil) was used for column chromatography, and TLC was carried out with pre-coated silica gel sheets on polyethylene $(0.20 \mathrm{~mm}$, MERCK, Germany). Fractions and compounds were monitored by TLC, and detected by spraying with a solution of vanillin/perchloric acid/EtOH, followed by heating for $5 \mathrm{~min}$ at $100^{\circ} \mathrm{C}$

Reagents and Drugs. Pentobarbital sodium salt (98\% purity), pilocarpine hydrochloride (98\%), perchloric acid p.a., reagent grade ethanol, 2-mercaptoethanol (99\%), ophthadialdehyde (99\%), pentylenetetrazole (99\%) and all amino acids (98-99\%) were purchased from Sigma Chem. Co. (St. Louis, MO, USA). Tween 80 and ethyl ether were from Vetec (Rio de Janeiro, Brazil). Diazepam $5 \mathrm{mg} / \mathrm{mL}$ ampoules from Cristália (São Paulo, Brazil) were diluted in distilled water for a $0.5 \mathrm{mg} / \mathrm{mL}$ final concentration, before use. All other drugs were of analytical grade.

Amino Acids Determination by HPLC. Mice were treated for 7 days with vehicle or AcAMY (10 and $25 \mathrm{mg} / \mathrm{kg}$, i.p.). Thirty minutes after the last administration, animals were killed by cervical dislocation, and the hippocampus and striatum were immediately removed on ice. After dissection, each area was weighted and conserved at $-70^{\circ} \mathrm{C}$ for use. A $10 \%$ homogenate was then prepared in $0.1 \mathrm{M}$ perchloric acid, and derivatized with the same volume of the ophthadialdehyde reagent solution. After a $60 \mathrm{~s}$ reaction period, a $20 \mu \mathrm{L}$ aliquot was injected into the HPLC with a 4 mm C18 reverse phase column (Shimadzu, Japan). The mobile phase A ( $\mathrm{pH} 6.95)$ was composed of sodium acetate $(0.1$ $\mathrm{M})$, methanol (6\%) and tetrahydrofuran (1.5\%), and flowed at $1.0 \mathrm{~mL} / \mathrm{min}$ in a $30 \mathrm{~min}$ gradient. The mobile phase $\mathrm{B}$ consisted of $100 \%$ methanol [11]. The fluorometric detector (model RF 535 from Shimadzu, Japan) had the excitation and emission wavelengths set at 370 and $450 \mathrm{~nm}$, respectively. In the hippocampus and striatum, the concentrations of free amino acids were determined by comparison of their peak areas with those of standard amino acids injected into the HPLC column, at the day of the experiment. Calculations were, then, carried out on the basis of the standard amino acids known concentrations. The results were expressed as $\mu \mathrm{g} / \mathrm{g}$ of wet tissue.

PTZ and Pilocarpine-Induced Convulsion Test. Animals were pretreated with AcAMY $(2.5,5,10$ or $25 \mathrm{mg} / \mathrm{kg}$ ), $30 \mathrm{~min}$ (i.p.) or $1 \mathrm{~h}$ (p.o.), before the administration of PTZ $(100 \mathrm{mg} / \mathrm{kg}$, i.p.) or pilocarpine $(400 \mathrm{mg} / \mathrm{kg}$, i.p.). After that, animals were placed into individual cages and observed for $30 \mathrm{~min}$. The latency time to the first convulsion and the death latency were the observed parameters [12]. Mice that did not show clonic or tonic convulsions, within $30 \mathrm{~min}$ of 
PTZ or pilocarpine administration, were considered protected. The control group received $0.5 \%$ Tween 80 .

Open Field Test. The open field arena was made of acrylic (transparent walls and black floor, $30 \times 30 \times 15 \mathrm{~cm}$ ), divided into sixteen squares of equal areas. The open field was used to evaluate the exploratory activity of the animal [13]. The test was performed inside a room with controlled temperature $\left(23^{\circ} \mathrm{C}\right)$, dim light and only one observer. Each animal was placed at the center of the arena, and allowed to explore it freely. The observed parameters were: ambulations (the number of squares crossed with all four paws), numbers for grooming and rearing, recorded for the last $5 \mathrm{~min}$ of the 6 min testing period. After each animal exposure, the apparatus was washed with a $5 \%$ alcohol/water solution (v/v), before using it again.

Elevated Plus Maze. This test has been widely validated for measuring anxiolytic and anxiogenic-like activities, in rodents [14]. The apparatus consisted of two opposite open arms $(30 \times 5 \mathrm{~cm})$, crossed by two closed arms of the same dimensions, with $25 \mathrm{~cm}$ high walls. The arms were connected to a $5 \times 5 \mathrm{~cm}$ central square. The apparatus was elevated $45 \mathrm{~cm}$ above the floor, in a dimly illuminated room. Mice were placed individually in the center of the maze, facing an enclosed arm, and the number of entries and time spent on the open arms were recorded for the next $5 \mathrm{~min}$. Entry into an arm was defined as the animal placing all four paws onto the arm. After each test, the maze was carefully cleaned up with a wet paper (10\% ethanol solution).

Sleeping Time Induced by Pentobarbital or Ethyl Ether. In this test, performed according to a previously described method [15], the sleep was induced by the intraperitoneal administration of $40 \mathrm{mg} / \mathrm{kg}$ pentobarbital, in mice pretreated $30 \mathrm{~min}$ before with AcAMY or vehicle. The sleep duration ( $\mathrm{min}$ ) of each animal was determined as the period for recovering the righting reflex, considered as the hypnosis endpoint. In the case of ethyl ether-induced sleeping time, the mice were treated with AcAMY or vehicle, and $30 \mathrm{~min}$ later each animal was placed under a glass funnel $(500 \mathrm{~mL}$ capacity) with an ethyl ether saturated atmosphere. After sleeping induction, the animals were removed from the chamber, and the sleeping duration (s) was recorded, as de- scribed above.

Statistical Analysis. All data represent mean \pm S.E.M. values. The data were analyzed by analysis of variance (ANOVA). Whenever ANOVA was significant, further multiple comparisons were undertaken, using the Dunnett or Tukey t-tests. All analyses were performed using the software Prism 3.0 for Windows. The level of statistical significance adopted was $\mathrm{p}<0.05$.

\section{RESULTS}

In the PTZ-induced convulsions model, alpha- and betaamyrin acetate $(5,10$ and $25 \mathrm{mg} / \mathrm{kg}$, i.p.) significantly increased the latency time to the first convulsion, in 42, 61 and $79 \%$, as compared to controls. A similar increase was observed after oral administration with the doses of $10(57 \%)$ and $25 \mathrm{mg} / \mathrm{kg}(77 \%)$. AcAMY also increased in 59, 97 and $127 \%$ the latency time to death, after intraperitoneal administration of 5,10 and $25 \mathrm{mg} / \mathrm{kg}$, respectively, while increases in this parameter of the order of 75 and $93 \%$ were observed after oral administration (10 and $25 \mathrm{mg} / \mathrm{kg}$, respectively), as shown in Table 1. In the pilocarpine-induced convulsions model, AcAMY at both doses was unable to alter the latency time to the first convulsion or the latency to death, unless after a higher dose (50 mg/kg, i.p.) was administered, as shown in Table 2.

AcAMY significantly increased in 37 and $35 \%$ the barbiturate-induced sleeping time, after its administration at the doses of 10 and $25 \mathrm{mg} / \mathrm{kg}$, i.p., respectively. After the oral administration and at the same doses, AcAMY also increased the sleeping time in 54 and $67 \%$, respectively. AcAMY was also tested on the ethyl ether-induced sleeping time, in order to clarify the putative hypno-sedative effect of the drug. The prolongation of barbiturate-induced sleeping time may be due to pharmacokinetic interactions, what is not the case with ethyl ether. We showed that AcAMY also significantly increased in 97 and 162\% the ethyl ether-induced hypnosis (Table 3), confirming the AcAMY sedative action.

AcAMY, at the doses of 2.5, 5, 10 e $25 \mathrm{mg} / \mathrm{kg} / \mathrm{i} . \mathrm{p}$., acutely administered $30 \mathrm{~min}$ before the experiment, did not alter the mice locomotor activity or the number of rearing, as compared to controls. However, significant decreases of the

Table 1. Anticonvulsant Effect of AcAMY on the PTZ-Convulsion Model in Mice

\begin{tabular}{|l|l|c|}
\hline \multicolumn{1}{|c|}{ Group } & Latency to the $\mathbf{1}^{\text {st }}$ Convulsion (s) & Latency to Death (s) \\
\hline \hline Control, i.p. & $53.2 \pm 1.9(25)$ & $185.3 \pm 14.5(20)$ \\
\hline AcAMY 2.5 mg/kg, i.p. & $61.2 \pm 8.1(8)$ & $238.3 \pm 54.9(8)$ \\
\hline AcAMY 5 mg/kg, i.p. & $75.3 \pm 16.9(8)$ & $294.8 \pm 60.8(8)$ \\
\hline AcAMY 10 mg/kg, i.p. & $85.9 \pm 6.2 *(16)$ & $364.9 \pm 43.5 *(16)$ \\
\hline AcAMY 25 mg/kg, i.p. & $95.3 \pm 10.4 *(10)$ & $420.9 \pm 31.9^{* *}(10)$ \\
\hline DZP 1 mg/kg, i.p. & $97.1 \pm 7.3 *(8)$ & $474.1 \pm 38.3 * *(8)$ \\
\hline Control, p.o. & $57.4 \pm 4.0(7)$ & $193.7 \pm 37.3(6)$ \\
\hline AcAMY 10 mg/kg, p.o. & $90.0 \pm 9.2(7)$ & $338.6 \pm 49.1 *(8)$ \\
\hline AcAMY 25 mg/kg, p.o. & $101.7 \pm 16.1 *(7)$ & $373.4 \pm 42.8^{*}(7)$ \\
\hline DZP 1 mg/kg, p.o. & $105.1 \pm 10.1 *(7)$ & $381.4 \pm 44.1 *(7)$ \\
\hline
\end{tabular}

Data are means \pm S.E.M of the number of animals in parentheses. $* \mathrm{p}<0.05,{ }^{*} \mathrm{p}<0.01$; ANOVA followed by Dunnett as the post-hoc test, as compared to the control group (treated with $0.5 \%$ Tween 80 ). 
Table 2. Anticonvulsant Effect of AcAMY on the Pilocarpine-Induced Convulsions in Mice

\begin{tabular}{|l|l|l|}
\hline \multicolumn{1}{|c|}{ Group } & Latency to the $\mathbf{1}^{\text {st }}$ Convulsion (s) & Latency to Death (s) \\
\hline \hline Control, i.p. & $190.0 \pm 19.2(12)$ & $321.8 \pm 38.4(10)$ \\
\hline AcAMY 10 mg/kg, i.p. & $192.6 \pm 16.7(8)$ & $282.4 \pm 29.0(8)$ \\
\hline AcAMY 25 mg/kg, i.p. & $222.6 \pm 28.8(9)$ & $395.0 \pm 42.5(8)$ \\
\hline AcAMY 50 mg/kg, i.p. & $326.0 \pm 25.8^{* *}(11)$ & $529.4 \pm 39.5^{* *}(11)$ \\
\hline DZP 5 mg/kg, i.p. & $485.0 \pm 14.8^{* * *(12)}$ & $735.4 \pm 29.5^{* * *(10)}$ \\
\hline
\end{tabular}

Data represent means \pm S.E.M of the number of animals in parentheses. ${ }^{* *} \mathrm{p}<0.01$ and $* * * \mathrm{p}<0.001$, ANOVA followed by Dunnett as the post hoc test, as compared to the control group (treated with $0.5 \%$ Tween 80 ).

order of 38, 62 and $65 \%$ were observed in grooming behavior, after the administration of 5,10 and $25 \mathrm{mg} / \mathrm{kg}$, respectively. The sub-chronic administration of AcAMY for 7 days, at the doses of 10 and $25 \mathrm{mg} / \mathrm{kg}$, i.p., produced significant reduction in the number of crossings (25 and $26 \%$, respectively). AcAMY also decreased the number of grooming (42 and 54\%) as well as the number of rearing (45 and 28\%). Diazepam $(1 \mathrm{mg} / \mathrm{kg}$, i.p. $)$, used as a positive control, significantly decreased in 56, 58 and $27 \%$ the numbers of crossing, grooming and rearing, respectively (Table 4).

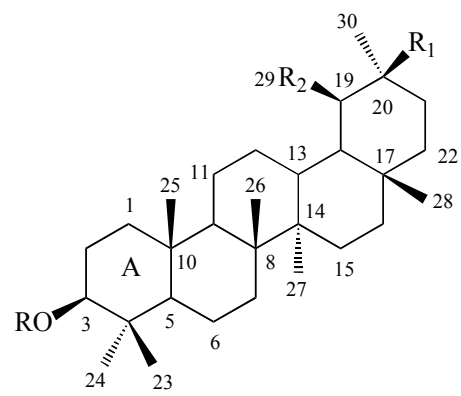

Fig. (1). (1) $\mathrm{R}=\mathrm{R}_{1}=\mathrm{H}, \mathrm{R}_{2}=\mathrm{CH}_{3}\left(\alpha\right.$-amyrin); (2) $\mathrm{R}=\mathrm{R}_{2}=\mathrm{H}, \mathrm{R}_{1}=$ $\mathrm{CH}_{3}$ ( $\beta$-amyrin); (1a) $\mathrm{R}=\mathrm{COCH}_{3}, \mathrm{R}_{1}=\mathrm{H}, \mathrm{R}_{2}=\mathrm{CH}_{3}$ (Acetate of $\alpha$ amyrin); (2a) $\mathrm{R}=\mathrm{COCH}_{3}, \mathrm{R}_{1}=\mathrm{CH}_{3}, \mathrm{R}_{2}=\mathrm{H}$ (Acetate of $\beta$-amyrin).

AcAMY presented a significantly anxiolytic activity, at the doses of 5,10 and $25 \mathrm{mg} / \mathrm{kg}$, i.p., as assessed by the elevated plus maze test, where it increased the number of entrances in the open arms (NEOA) by 33,39 and $82 \%$, as well as the time spent in the open arms (TSOA) by 29, 88 and $97 \%$, respectively, as compared to controls. AcAMY, at the doses of 10 and $25 \mathrm{mg} / \mathrm{kg}$, i.p., also decreased by 42 and $46 \%$ the time spent in the closed arms (TSCA), The number of entrances in the closed arms (NECA) was altered only with the higher dose (a 38\% decrease at the dose of 25 $\mathrm{mg} / \mathrm{kg}$ ), as compared to controls.

AcAMY, administered daily and intraperitoneally for 7 days, altered all parameters studied. Thus, NEOA was increased by 24 and $68 \%$, at the doses of 10 and $25 \mathrm{mg} / \mathrm{kg}$, while TSOA was increased by 50 and $105 \%$, respectively. On the other hand, NECA was decreased by 30 and $49 \%$, and the TSCA was also decreased by 36 and $61 \%$, respectively, with the same doses. Diazepam (1 mg/kg, i.p.), used as a positive control, significantly increased NEOA and TSOA by 54 and $60 \%$, and decreased NECA and TSCA by 45 e $60 \%$, respectively. Data from the elevated plus maze experiment are presented in Table $\mathbf{5}$.
Only the $25 \mathrm{mg} / \mathrm{kg}$ AcAMY dose (i.p., for 7 days) was effective in modifying amino acids concentrations. Referring to both cerebral areas (striatum and hippocampus), there was an $89 \%$ increase of tyrosine levels in the hippocampus, whereas other amino acids were unaltered. In the striatum, alterations were more evident and complex. Thus, tyrosine and taurine were increased by 97 and 79\%, respectively, while there was a decrease in aspartate, GABA and glutamate of the order of 72,55 and $60 \%$, respectively. Triptophan and glycine did not change in this brain area (Fig. 2).

\section{DISCUSSION}

We recently showed [2] that the mixture of two pentacyclic triterpenes, alpha- and beta-amyrin, is highly active in the central nervous system, presenting anxiolytic and antidepressant activities, when acutely administered to mice, as assessed by the elevated plus maze and forced swimming tests. Single or subchronic administrations of AcAMY, the acetylated mixture, were used at doses ranging from 2.5 to $25 \mathrm{mg} / \mathrm{kg}$, i.p.

We showed that AcAMY exhibits a potent anticonvulsant effect, in the model of PTZ-induced convulsions, but not in pilocarpine-induced convulsions, unless at a higher dose range. The pentylenetetrazole kindling model is characterized by an increased susceptibility to seizures, following injection of initially sub-convulsive doses of PTZ, culminating in generalized tonic-clonic seizures. PTZ is a selective blocker of the chloride ionophore complex to the $\mathrm{GABA}_{\mathrm{A}}$ receptor and, after repeated or single dose administrations, leads to a decrease in GABAergic function [16] and to the stimulation and modification of density or sensitivity of different glutamate receptor subtypes, in many brain regions [17]. PTZ may also trigger a variety of biochemical processes, including the activation of membrane phospholipases, proteases, and nucleases [18]. In the PTZ-induced convulsions, AcAMY administered by the oral or intraperitoneal routes showed a significant increase in the latency to the first convulsion, as well as an increase in the latency to death.

Recently, pilocarpine was reported to significantly increase brain malondialdehyde levels, a marker of lipid peroxidation [19]. An increase was also observed in catalase and superoxide dismutase activities, two important antioxidant enzymes. Furthermore, these authors also reported that pilocarpine induces oxidative damage, and increases antioxidant enzyme activities and expression in the brain cortex, leading to excitotoxicity and cell death [20]. In the model of 

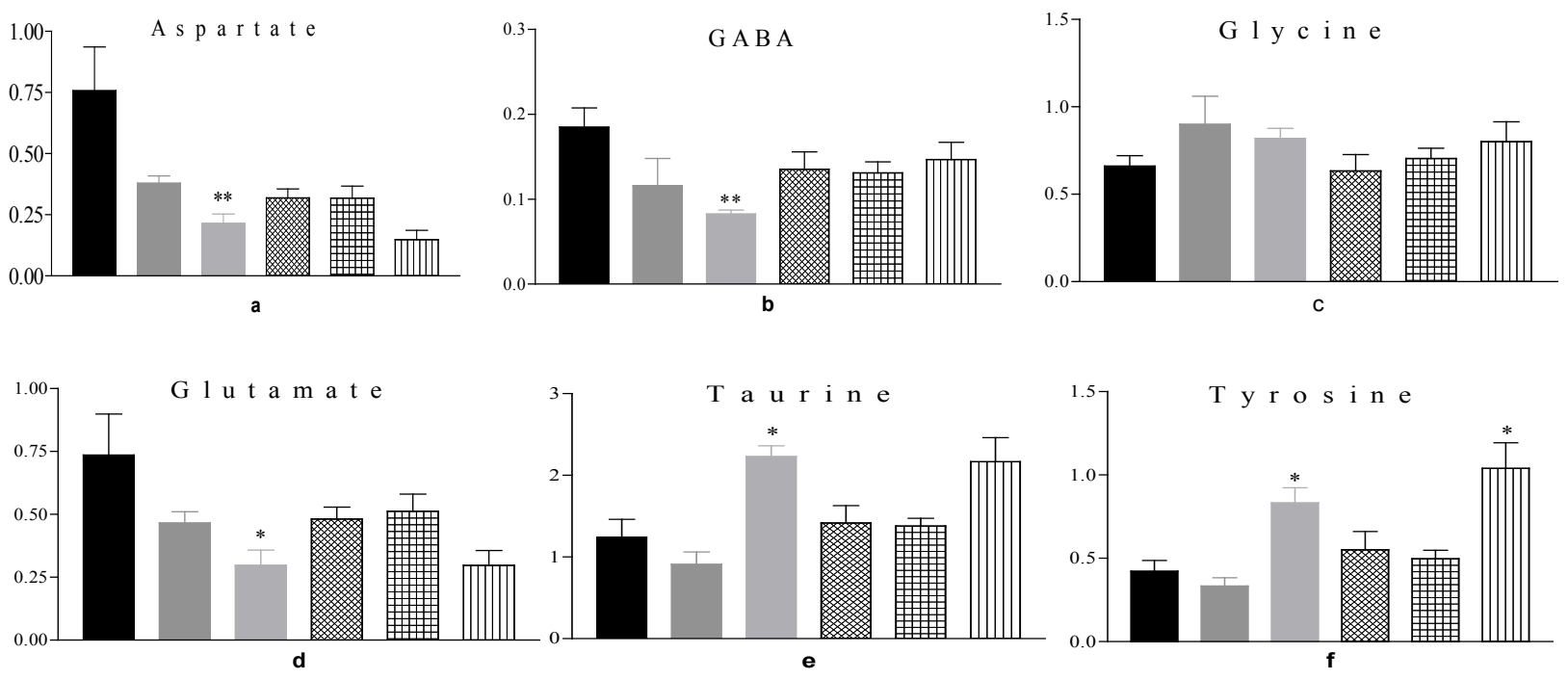

T r y p t o p h a n

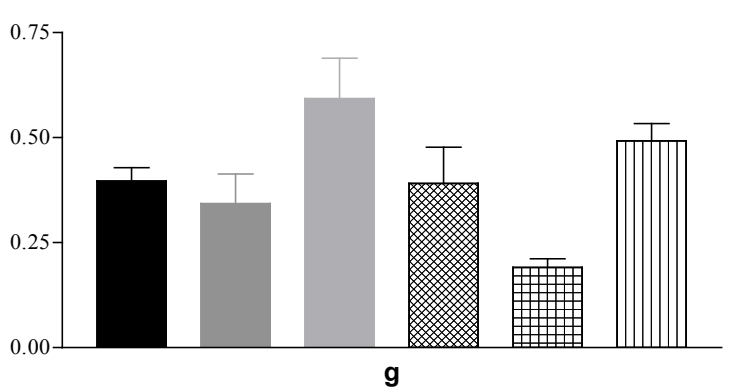

Ct-st

AcAMY10-st

AcAMY25-st

Ct-hp

\#再AMY10-hp

एा] AcAMY25-hp

Fig. (2). Animals were treated for 7 days and killed by decapitation, $30 \mathrm{~min}$ after the last dose. The striatum and hippocampus were dissected and kept at $-70^{\circ} \mathrm{C}$ for amino acid determination ( $\mu \mathrm{g} / \mathrm{g}$ de tecido) by HPLC. Each column represents the mean $\pm \mathrm{S} . \mathrm{E} . \mathrm{M}$ of 5-14 animals per group. ${ }^{*} \mathrm{p}<0.05$ and $* * \mathrm{p}<0.01 ; * * * \mathrm{p}<0.01$, ANOVA followed by Tukey as the post hoc test, as compared to the control group (treated with $0.5 \%$ of Tween 80 ). Legends: $\mathrm{Ct}=$ control, $\mathrm{AcAMY}=$ alpha- and beta-amyrin acetate, $\mathrm{st}=$ striatum and hp $=$ hippocampus. 10 and $25=$ doses of 10 and $25 \mathrm{mg} / \mathrm{kg}$, i.p.

Table 3. AcAMY Increases (A) Pentobarbital- and (B) Ethyl Ether-Induced Sleeping-Times in Mice

\begin{tabular}{|l|c|}
\hline \multicolumn{1}{|c|}{ Group } & Sleep Latency \\
\hline \hline A. Pentobarbital-Induced Sleeping Time (min) & \\
Control, i.p & $45.7 \pm 6.0(10)$ \\
AcAMY 10 mg/kg, i.p. & $71.9 \pm 5.0^{*}(11)$ \\
AcAMY 25 mg/kg, i.p. & $76.7 \pm 5.3^{* *}(10)$ \\
DZP 0.5 mg/kg, i.p. & $202.1 \pm 7.8^{* *(10)}$ \\
Control, p.o. & $48.5 \pm 4.1(13)$ \\
AcAMY 10 mg/kg,p.o. & $74.6 \pm 7.4^{* *(14)}$ \\
AcAMY 25 mg/kg,p.o. & $80.9 \pm 4.0^{* *}(14)$ \\
DZP 0.5 mg/kg, p.o. & $180.4 \pm 3.8^{* *}(10)$ \\
B. Ethyl ether-induced & \\
sleeping time (s) & \\
Control, i.p. & $64.9 \pm 5.4(10)$ \\
AcAMY 10 mg/kg, i.p. & $128.4 \pm 7.6^{*}(10)$ \\
AcAMY 25 mg/kg, i.p. & $170.3 \pm 15.8^{* * *}(10)$ \\
DZP 1 mg/kg, i.p. & $230.8 \pm 26.2^{* *}(10)$ \\
\hline
\end{tabular}

Data represent means \pm S.E.M of the number of animals in parentheses. $p<0.05, * * p$ $<0.01$ and $* * *$ p $<0.001$, ANOVA followed by Dunnett as the post hoc test, as compared to the control group (treated with $0.5 \%$ Tween 80 ) pilocarpine-induced convulsions, AcAMY did not alter the latency time to the first convulsion, nor the latency time to death, unless at its highest dose $(50 \mathrm{mg} / \mathrm{kg}$, i.p.).

In the barbiturate-induced sleeping time, AcAMY was able to increase the animal's sleeping time, after oral or intraperitoneal administration of both doses utilized. Drugs known to decrease the sleep latency or increase sleep time are considered as CNS depressors [21], and this effect was confirmed by the prolongation of the ethyl ether sleeping time by AcAMY. Unlikely ethyl ether, the prolongation of the pentobarbital-induced sleeping time may be due to pharmacokinetic interactions. Thus, some drugs can interact with the cytochrome $\mathrm{P} 450$ complex and promote a potentiation of the CNS depressant effect of barbiturates, without exerting any central action. The inhibitory neurotransmitter GABA is the molecular target of sedative/hypnotic drugs, and several of them bind to the $\mathrm{GABA}_{\mathrm{A}}$ receptor in the brain [22]. In the present case, similarly to what we showed before for AMY [2], mechanisms involving GABAergic neurotransmission will probably play a role in the potentiation of barbiturateinduced sleeping time, seen with AcAMY.

In order to evaluate the sedative activity of AcAMY, the open field test was used. We showed that AcAMY was ineffective when acutely administered by the oral or intraperito- 
Table 4. Effect of the Acute and Sub-Chronic Intraperitoneal Administration of AcAMI (2.5 to $25 \mathrm{mg} / \mathrm{kg})$ on the Open Field Test in Mice

\begin{tabular}{|l|l|l|l|}
\hline \multicolumn{1}{|c|}{ Group } & Number of Crossings & Grooming & Rearing \\
\hline \hline Control (30 min) & $42.0 \pm 1.8(19)$ & $6.2 \pm 1.2(20)$ & $29.9 \pm 2.1(18)$ \\
\hline AcAMY 2.5 (30 min) & $36.7 \pm 2.4(7)$ & $5.0 \pm 0.8(6)$ & $31.8 \pm 4.9(6)$ \\
\hline AcAMY 5.0 (30 min) & $32.0 \pm 1.5^{*}(7)$ & $3.8 \pm 0.8(6)$ & $27.2 \pm 3.1(6)$ \\
\hline AcAMY 10 (30 min) & $45.6 \pm 3,9(7)$ & $2.3 \pm 0.4(6)$ & $32.8 \pm 2.1(6)$ \\
\hline AcAMY 25 (30 min) & $37.4 \pm 1.8(7)$ & $2.2 \pm 0.5(6)$ & $31.5 \pm 3.0(6)$ \\
\hline DZP 1 (30 min) & $31.4 \pm 1.3 *(7)$ & $1.4 \pm 0.5^{*}(6)$ & $20.5 \pm 2.0^{*}(6)$ \\
\hline Control (7 d) & $53.6 \pm 2.5(12)$ & $8.2 \pm 0.9(11)$ & $35.6 \pm 1.3(10)$ \\
\hline AcAMY 10 (7 d) & $40.2 \pm 1.3^{* *}(8)$ & $4.3 \pm 0.6^{* *}(9)$ & $19.6 \pm 2.7 *(9)$ \\
\hline AcAMY 25 (7 d) & $39.4 \pm 3.9^{* *}(5)$ & $3.8 \pm 0.8^{* *}(6)$ & $25.8 \pm 2.2^{*}(6)$ \\
\hline DZP 1 (7 d) & $23.8 \pm 0.9^{* *}(10)$ & $3.4 \pm 0.8^{* *}(10)$ & $26.0 \pm 2.0^{*}(6)$ \\
\hline
\end{tabular}

Data represent means \pm S.E.M of the number of animals in parentheses. ${ }^{*} \mathrm{p}<0.05,{ }^{* *} \mathrm{p}<0.01$; ANOVA followed by Dunnett as the post hoc test, as compared to the control group (treated with $0.5 \%$ of Tween 80 ).

neal routes, at the two tested doses (10 and $25 \mathrm{mg} / \mathrm{kg}$ ). Recent studies [23] reported that the mixture of alpha- and betaamyrin (3 to $200 \mathrm{mg} / \mathrm{kg}$, p.o.) neither significantly altered the pentobarbital sleeping time, nor impaired the ambulation or motor coordination, in the open field and rota rod tests, indicating the absence of sedative or motor abnormalities, in mice. In the present work, we observed that, after subchronic administration (once daily for 7 days), AcAMY presented a sedative activity, at both doses, altering all the parameters studied in the open field test, such as numbers of crossing, rearing and grooming, similarly to diazepam used as a positive control. Our results agree with earlier data [24] demonstrating a significant decrease of spontaneous locomotor activity of mice treated with beta-amyrin palmitate, at doses ranging from 2.5 to $10 \mathrm{mg} / \mathrm{kg}$, and indicating a sedative property of this amyrin ester.
The evaluation of the anxiolytic property of AcAMY was carried out with the elevated plus maze test. According to Barrett, 1991 [25], an anxiolytic effect is suggested when the drug increases entries into the open arms, without altering the total number of arm entries. Mice acutely or subchronically treated with AcAMY altered all the parameters studied, and significantly increased the number of entrances as well as the time spent in the open arms, indicating a potent anxiolytic activity. We also showed recently [2] that the alpha- and beta-amyrin mixture exerts potent sedative, anxiolytic and antidepressant activities that probably involve GABAergic as well as noradrenergic mechanisms. We can not exclude that alterations in these neurotransmitter systems also play a role in the present work.

The brain extracellular concentration of amino acids, such as glutamate, glycine, aspartate and GABA, has a particular importance in pathological processes, including epi-

Table 5. Effect of the Intraperitoneal Administration of AcAMY on the Elevated Plus Maze Test in Mice

\begin{tabular}{|l|c|c|c|c|}
\hline \multicolumn{1}{|c|}{ Group } & NEOA & NECA & TSOA & TSCA \\
\hline \hline $\begin{array}{l}\text { 30 min } \\
\text { Control }\end{array}$ & $4.4 \pm 0.2(20)$ & $7.6 \pm 0.4(20)$ & $88.5 \pm 7.3(20)$ & $157.7 \pm 6.8(20)$ \\
\hline AcAMY 2.5 & $4.5 \pm 0.7(8)$ & $7.5 \pm 1.2(8)$ & $81.8 \pm 12.2(8)$ & $166.4 \pm 6.8(8)$ \\
\hline AcAMY 5 & $5.9 \pm 0.8(8)$ & $6.8 \pm 0.8(8)$ & $114.3 \pm 19.1(8)$ & $137.1 \pm 16.3(8)$ \\
\hline AcAMY 10 & $6.1 \pm 0.5(8)$ & $5.9 \pm 0.5(9)$ & $166.5 \pm 9.7 * *(8)$ & $91.6 \pm 7.5^{* *}(9)$ \\
\hline AcAMY 25 & $8.0 \pm 0.5^{* *}(8)$ & $4.6 \pm 0.5^{* *}(9)$ & $174.3 \pm 12.5^{* *}(10)$ & $85.8 \pm 9.9^{* *}(9)$ \\
\hline DZP & $9.4 \pm 0.4 * *(8)$ & $4.5 \pm 0.5^{* *}(10)$ & $187.4 \pm 10.9 * *(8)$ & $79.2 \pm 9.2^{* *}(8)$ \\
\hline 7 days & $5.4 \pm 0.4(8)$ & $8.8 \pm 0.5(10)$ & $103.4 \pm 11.3(9)$ & $148.2 \pm 9.1(10)$ \\
\hline Control & $8.3 \pm 0.6^{*}(7)$ & $4.9 \pm 0.7^{*}(8)$ & $165.1 \pm 20.5^{* *}(6)$ & $99.9 \pm 17.8^{*}(8)$ \\
\hline AcAMY 10 & $6.7 \pm 0.9(6)$ & $6.2 \pm 0.9^{*}(6)$ & $154.7 \pm 13.6^{*}(6)$ & $95.4 \pm 8.7^{*}(5)$ \\
\hline AcAMY 2 & $9.0 \pm 0.8^{* *}(8)$ & $4.5 \pm 0.6^{* *}(8)$ & $212.0 \pm 8.4^{* *}(7)$ & $57.5 \pm 10.9^{* *}(8)$ \\
\hline DZP & & & & \\
\hline
\end{tabular}

$\mathrm{NEOA}=$ number of entries in the open arms; NECA $=$ number of entries in the closed armas; TSOA = time spent in the open arms; TSCA = time spent in the closed arms. Data represent means \pm S.E.M of the number of animals in parentheses. ${ }^{*} \mathrm{p}<0.05,{ }^{* *} \mathrm{p}<0.01$; ANOVA followed by Dunnett as the post hoc test, as compared to the control group (treated with $0.5 \%$ of Tween 80 ). 
lepsy, stroke, and other neurodegenerative disorders [26]. Steroid hormones and their metabolites, such as pregnenolone and allopregnenolone, are neuroactive, due to their ability to modulate activity at glutamate and $\mathrm{GABA}_{\mathrm{A}}$ receptors, respectively [27]. AcAMY is a triterpene chemically similar to steroids. Furthermore, the anticonvulsant, sedative and anxiolytic effects shown by AcAMY in the present study may reflect the observed alterations in amino acids contents. The increase of tyrosine in both brain areas may be related to the antidepressant activity, as that presented by AMY before esterification. In a recent work [2], we reported that this effect involves the noradrenergic system, but not the serotonergic one. This agrees with the fact that, in the present work, we did not find any alterations in tryptophan levels, the precursor of serotonin.

More than half of all CNS neurons utilize glutamate and aspartate, main excitatory neurotransmitters. Glutamate is responsible for $75 \%$ of the CNS depolarizing activity, and has been implicated in the initiation and spread of seizure activity [28]. Thus, AcAMY decreased not only glutamate and aspartate concentrations, but also GABA concentrations (GABA is synthesized from glutamate). An earlier study [29], performed with synaptosomes from brain tissue of patients with temporal lobe epilepsy, showed reductions in glutamine and GABA concentrations as well as the glutamine/glutamate ratio. These data suggest that alterations in the balance between excitatory and inhibitory amino acids may be involved in the expression of epilepsy. We also showed that, after AMY treatment, striatal taurine concentrations were increased, whereas no change was seen in the glycine content. Taurine, an amino acid that abounds in the brain, has been implicated in inhibitory neuromodulation and osmoregulation. Thus, increased taurine levels lead to a reduced frequency in epileptic crises, membrane stabilization and balance in glutamate levels, as assessed by animal models [30].

Furthermore, expressions of glutamate and GABA were shown to be inhibited in the hippocampus of rats submitted to chronic kindling by saikosaponins which are triterpenes, as alpha- and beta-amyrin. Also, ginsenoside $\mathrm{Rh}(2)$ inhibited the sodium channel function and sodium channel-activated release of neurotransmitters, including glutamate and GABA, in synaptic fractions from mouse brain [31, 32].

Recent studies showed that synthetic derivatives of alpha- and beta-amyrin, including their acetates, present mostly a qualitatively different pharmacological profile what agrees with our data [33, 34].

Altogether, we concluded that the mechanisms of action of the sedative, anticonvulsant and anxiolytic effects of AcAMY probably involve a decrease in excitatory amino acids contents (glutamate and aspartate) and an increase in the concentration of taurine, considered as an inhibitory amino acid. Furthermore, the GABAergic neurotransmission, but not the cholinergic one, may also play a role. However, other studies have to be carried out, in order to further clarify the mechanism of action of AcAMY.

\section{ACKNOWLEDGEMENTS}

The authors are grateful to the technical assistance of Ms. M.V.R. Bastos and to Prof. M.O.L. Viana for the manuscript orthographic revision. The work had the financial support of the Brazilian National Research Council.

\section{REFERENCES}

[1] Bandeira, P.N.; Lemos, T.L.G.; Costa, S.M.O.; Santos, H.S. Obtenção de derivados da mistura triterpenóidica $\alpha$ e $\beta$-amirina. Rev. Bras. Farmacog., 2007, 17, 204-208.

[2] Aragão, G.F.; Carneiro, L.M.V.; Junior, A.P.F.; Vieira, L.C.; Bandeira, P.N.; Lemos, T.L.G.; Viana, G.S. A possible mechanism for anxiolytic and antidepressant effects of alpha- and beta amyrin from Protium heptaphyllum (Aubl) March. Pharmacol. Biochem. Behav., 2006, 85, 827-834.

[3] Kweifio-Okai, G.; Macrides, T. Antilipoxygenase activity of amyrin triterpenes. Res. Commun. Chem. Pathol. Pharmacol., 1992, 78, 367-72.

[4] Rocha, G.G.; Simões, M.; Lúcio, K.A.; Oliveira, R.R.; Coelho, M.A.K.; Gatass, C.R.; Sudo, R.T.; Zapara-Sudo, G. Natural triterpenoides from Cecropia lyratiloba are cytotoxic to both sensitive and multidrug resistant leukemia cell lines. Bioorg. Med. Chem., 2007, 15, 7355-7360.

[5] Jayakumar, G.; Ajithabai, M.D.; Santhosh, B.; Veena, C.S.; Nair, M.S. Microwave assisted acetylation and deacetylation studies on the triterpenes isolated from Dysoxylum malabaricum and Dysoxylum beddomei. Indian J. Chem., 2003, 42, 429-431.

[6] Syrovets, T.; Buchele, B.; Krauss, C.; Laumonnier, Y.; Simmet, T. Acetyl-Boswellic acids inhibit lipopolysaccharide-mediated TNF- $\alpha$ induction in monocytes by direct interaction with IкB kinases. $J$. Immunol., 2005, 174, 498-506.

[7] Poeckel, D.; Werz, O. Boswellic acids: biological actions and molecular targets. Curr. Med. Chem., 2006, 13, 3359-3369.

[8] Hoernlein, R.F.; Orlikowsky, T.; Zehrer, C.; Niethammer, D. Sailer, E.R.; Simmet, T.; Dannecker, G.E.; Ammon, H.P. Acetyl11-keto-beta-boswellic acid induces apoptosis in HL-60 and CCRF-CEM cells and inhibits topoisomerase I. J. Pharmacol. Exp. Ther., 1999, 288, 613-619.

[9] Bandeira, P.N.; Pessoa, O.D.L.; Trevisan, M.T.S.; Lemos, T.L.G. Metabólitos secundários de Protium heptaphyllum MARCH. Química Nova, 2002, 25, 1078-1010.

[10] Mahato, S.B.; Kundu, A.P. ${ }^{13}$ C NMR Spectra of pentacyclictriterpenoides - A compilation and some salient features. Phytochemistry, 1994, 37, 1517-1575.

[11] Massieu L, Tapia R. Glutamate uptake impairment and neuronal damage in young and aged rats in vivo. J. Neurochem., 1997, 69, 1151-1160.

[12] Czuczwar, S.J.; Frey, H.H. Effect of morphine and morphine-like analgesics on susceptibility to seizures in mice. Neuropharmacol., 1986, $25,465-469$.

[13] Archer, J. Tests for emotionality in rats and mice: a review. Anim Behav., 1973, 21, 205-235.

[14] Lister, R.G. The use of a plus-maze to measure anxiety in the mouse. Psychopharmacol., 1987, 92, 180-185.

[15] Ferrini, R.; Miragoli, G.; Taccardi, B. Neuropharmacological studies on SB 5833, a new psychotherapeutic agent of the benzodiazepine class. Arzneimittel-Forschung, 1974, 24, 2029-2032.

[16] Corda, M.G.; Orlandi, M.; Lecca, D.; Giorgi, O. Decrease in GABAergic function induced by pentylenetetrazol kindling in rats: antagonism by MK-801. J. Pharmacol. Exp. Ther., 1992, 262, 792800.

[17] Rauca, C.; Zerbe, R.; Jantze, H. Formation of free hydroxyl radicals after pentylenetetrazol-induced seizure and kindling. Brain Res., 1999, 847, 347-351.

[18] Costa, L.G. Cell signaling and neurotoxic events; Chang, LW.; Ed.; Principles of Neurotoxicology. New York: Marcel Dekker: 1994, pp. 475-493.

[19] Tejada, F.R.; Nagy, P.I.; Xu, M.; Wu, C.; Katz, T.; Dorsey, J.; Rieman, M.; Lawlor, E.; Warrier, M.; Messer, W.S. Jr. Design and synthesis of novel derivatives of the muscarinic agonist tetra (ethyleneglycol) (3-methoxy-1,2,5-thiadiazol-4-yl) [3-(1-methyl 1,2,5,6 tetrahydropyrid-3-yl)-1,2,5-thiadiazol-4-yl] ether (CDD-0304): effects of structural modifications on the binding and activity at muscarinic receptor subtypes and chimeras. J. Med. Chem., 2006, 49, 7518-7531.

[20] Tejada, S.; Sureda, A.; Roca, C.; Gamundí, A.; Esteban, S. Antioxidant response and oxidative damage in brain cortex after high dose of pilocarpine. Brain Res. Bull., 2007, 71, 372-375. 
[21] Willianson, E.; Okpako, D.; Evans, F.J. Selection, Preparation and Pharmacological Evaluation of Plant Material, Wiley, Chichester, 1996.

[22] Doble, A. New insights into the mechanism of action of hypnotics. J. Psychopharmacol., 1999, 13, 11-20.

[23] Oliveira, F.A.; Vieira-Júnior, G.M.; Chaves, M.H.; Almeida, F.R.; Santos, K.A.; Martins, F.S.; Silva, R.M.; Santos, F.A.; Rao, V.S. Gastroprotective effect of the mixture of alpha- and beta-amyrin from Protium heptaphyllum: role of capsaicin-sensitive primary afferent neurons. Planta Med., 2004, 70, 780-782.

[24] Subarnas, A.; Tadano, T.; Kisara, K.; Ohizumi, Y. An alphaadrenoceptor-mediated mechanism of hypoactivity induced by beta-amyrin palmitate. J. Pharm. Pharmacol., 1993, 45, 10061008.

[25] Barrett, J.E. Animal behavior models in the analysis and understanding of anxiolytic drugs acting at serotonin receptors. Olivier, B.; Mos, J.; Slangen, J.L.; Eds.; Animal models in psychopharmacology. Basel' Birkhauser Verlag, 1991, pp. 37-52.

[26] Vajda, F.J. Neuroprotection and neurodegenerative disease. J. Clin. Neurosci., 2002, 9, 4-8.

[27] Gee, K.W.; Bolge, M.B; Brinton, R.E; Coirini, H.; McEwen, B.S. Steroid modulation of the chloride ionophore in rat brain: structureactivity requirements, regional dependence and mechanism of action. J. Pharmacol. Exp. Ther., 1988, 246, 803-812.

[28] Feng, Y.; LeBlanc, M.H.; Regunathan, S. Agmatine reduces extracellular glutamate during pentylenetetrazole-induced seizures in rat brain: a potential mechanism for the anticonvulsive effects. Neurosci. Lett., 2005, 390, 129-133.

[29] Labiner, D.M.; Yan, C.C.; Weinand, M.E.; Huxtable, R.J. Disturbances of Amino Acids from Temporal Lobe Synaptosomes in Human Complex Partial Epilepsy. Neurochem. Res., 1999, 24, 1379-1383.

[30] Hilgier, W.; Olson, J.E.; Albrecht, J. Relation of taurine transport and brain edema in rats with simple hyperammonemia or liver failure. J. Neurosci. Res., 1996, 45, 69-674.

[31] Xie, W.; Li, C.Z.; Bao, Y.; Yu, L.J. Salkosaponins inhibit increased glutamate and GABA expressions in the hippocampus of pentetrazole-induced slow kindling rats. Nan Fang Yi Ked a Xиe Xие Bao, 2006; 26, 1132-1135.

[32] Duan, Y.; Nicholson, R.A. 20(S)-protopanaxadiol and the ginsenoside $\mathrm{Rh}(2)$ inhibit the $\mathrm{Na}+$ channel-activated depolarization and $\mathrm{Na}+$ channel-dependent amino acid neurotransmitter release in synaptic fractions isolated from mammalian brain. Comp. Biochem. Physiol. C Toxicol. Pharmacol., 2008, 147, 351-356.

[33] Narender, T.; Khaliq, T.; Singh, A.B.; Joshi, M.D.; Mishra, P.; Chaturvedi, J.P.; Srivastava, A.K.; Maurya, R.; Agarwal, S.C. Synthesis of alpha-amyrin derivatives and their in vivo antihyperglicemic activity. Eur. J. Med. Chem., 2008 [Epub ahead of print].

[34] Soldi, C.; Pizzolatti, M.C.; Luiz, A.P.; Marcon, R.; Meotti, F.C.; Mioto, L.A.; Santos, A.R.S. Synthetic derivatives of the alpha- and beta-amyrin triterpenes and their antinociceptive properties. Bioorg. Med. Chem., 2008, 16, 3377-3386. 